\title{
Online Learning Satisfaction and Internet Addiction During Covid-19 Pandemic: A Two-Wave Longitudinal Study
}

\author{
Metin Besalti ${ }^{1}$ (D) . Seydi Ahmet Satici ${ }^{1}$ (D)
}

Accepted: 10 January 2022 / Published online: 26 January 2022

(c) Association for Educational Communications \& Technology 2022

\begin{abstract}
Stay-at-home orders and quarantines have not only shifted traditional face-to-face learning to online learning, but have also led to greatly increased consumption of digital devices during the coronavirus (COVID-19) pandemic. Thus, many students who were new to online learning were forced into a new environment. The purpose of this two-wave longitudinal study is to investigate the effects of internet addiction on online students' learning satisfaction during the COVID-19 pandemic. A total of two hundred and forty-nine undergraduate-level students from 51 of the 81 cities in Turkey completed an online questionnaire. The data used cross-lagged structural equation modeling. The results indicated that internet addiction at Time 1 decreased online students' learning satisfaction at Time 2 . The results also revealed that online students' learning satisfaction (Time 1) did not affect internet addiction (Time 2). It is concluded that internet-addicted students had lower learning satisfaction in online learning environments. Thus, it is essential for institutions to provide effective online instruction, psychological coping tools, and social and behavioral support, which may help reduce internet addiction and minimize its negative impacts on online learning environments during the pandemic.
\end{abstract}

Keywords Online learning satisfaction $\cdot$ Internet addiction $\cdot$ COVID-19 $\cdot$ Longitudinal

\section{Introduction}

The entire world has been grappling with a new pandemic called COVID-19 since it first emerged in the city of Wuhan, in the Hubei Province of China on 12th December 2019. COVID-19 which has become a contagious and fatal epidemic, has shown a wide range of symptoms such as fever, cough, and shortness of breath on the respiratory tract. Soon after, it was declared as a pandemic by the World Health Organization on 11th March 2020 due to the rapid increase in cases and deaths worldwide (WHO, 2020). Turkey has also been dealing with issues caused by coronavirus similar to those experienced in all other countries around the world. The first case in Turkey was reported on $11^{\text {th }}$ March 11 2020, and towards the end of February 2021 there were approximately 2,700,000 confirmed cases of COVID-19

Metin Besalti

besalti@artvin.edu.tr

Seydi Ahmet Satici

sasatici@artvin.edu.tr

1 Department of Educational Sciences, Artvin Coruh University, Artvin, Turkey with 28,569 deaths (Republic of Turkey Ministry of Health, 2021). To prevent the spread of the virus, Turkish authorities have taken timely precautions including issuing stay-athome orders and temporarily shutting down public places and educational institutions.

Turkey was not the only country to cease educational activities due to COVID-19. According to the United Nations Educational, Scientific and Cultural Organization (UNESCO), 172 countries and more than 1.5 billion students (which is about $90 \%$ of the world's student population) have been affected by school closures due to the coronavirus pandemic across the world (UNESCO, 2020). Due to these closures, educational practices have dramatically changed to stop the spread of COVID-19; shifting from traditional face-to-face learning to online learning in all education and training activities for schools.

Online learning offers multiple opportunities such as making education accessible to larger numbers of people (Mehrotra et al., 2001), providing a flexible and versatile learning environment with an effective interaction between instructor and learner (Franchi, 2020), creating a medium where online learning sessions can be arranged anywhere and anytime (Nortvig et al., 2018), and attracting more 
students to complete their educational goals at a lower cost (Green, 2010). However, these opportunities can only be achieved with the efficient and successful use of online teaching platforms (Roe et al., 2010). During the COVID19 pandemic, universities have been one of the most affected educational institutions. They had to start immediately to deliver instruction using online teaching platforms. This sudden and unexpected transition to online learning caused numerous difficulties and challenges especially for the students (Kaur, 2020). Many students were unfamiliar with online education, and it was challenging for them to take responsibility for their learning through online learning platforms (Korkmaz \& Toraman, 2020). Students' level of satisfaction with online learning therefore, has also been affected because of the COVID-19 pandemic.

Learning satisfaction can be defined as the perception of the students regarding the experience of the course, and the perceived value of the education obtained from an educational institution (Bolliger, 2004). Students' level of satisfaction with online learning is one of the most important indicators of the quality of online learning experiences (Ilgaz \& Gulbahar, 2015; Yukselturk \& Yildirim, 2008). Several factors affect students' satisfaction in online learning. Effective online interactions (Moore, 2014), perceived usefulness of the learning management systems (Sun et al., 2008), quality of the course designs and assessment process (Naveh et al., 2010), and students' computer literacy and self-efficacy skills (Liaw, 2008) are all factors that can affect students' level of satisfaction in online learning environments. In addition to these, it can be predicted that students' excessive internet use during the pandemic may also be a factor that affects their level of learning satisfaction in online learning.

\section{Internet Addiction during COVID-19 Pandemic}

COVID-19 has significantly reshaped not only the way of social life but also the way of delivering instruction. Consumption of digital entertainment, particularly the use of the internet has increased because of stay-at-home mandates and quarantines during the pandemic (e.g., Dong et al., 2020; Duan et al., 2020; Gómez-Galán et al., 2020). With the pandemic, people started to spend more time on social media tools, shopped online, watched movies, and played online games more than usual by connecting to the internet (Nielsen Global Media, 2020). Students especially, spent more time than ever on the internet because they were required to use it for educational purposes (Dong et al., 2020). Although a reasonable use of the internet is helpful for students, excessive and uncontrolled internet use can lead to internet addiction; which is defined as the inability of individuals to control their internet usage without thinking about its negative consequences (Griffiths, 2000).
Internet addiction causes psychological and social problems in the lives of younger generations (Cerniglia et al., 2017). Excessive use of the internet can cause depression, anxiety, and stress (İskender \& Akin, 2010; Moreno et al., 2013) which negatively affect the students' well-being and satisfaction (Błachnio et al., 2019; Sharma \& Sharma, 2018; Çikrıkci, 2016; Bozoglan et al., 2013; Wang et al., 2013). For instance; Błachnio et al. (2019) conducted a study to investigate the relationship between internet addiction and satisfaction in the USA and Italy. The results of the crosssectional analysis indicated that internet addiction was associated with lower life satisfaction among the participants. A similar study was done by Bozoglan et al. (2013) in Turkey with comparable results. They found that college students who tended to use the internet excessively had a lower level of satisfaction in their life. Besides this, excessive internet use has also been concluded to be the cause of school-related problems and challenges (Stavropoulos et al., 2013). Recent research studies show that internet addiction is negatively associated with students' academic performance (e.g., Huang et al., 2009; Stavropoulos et al., 2013; Yang \& Tung, 2007). Therefore, internet addiction may not only have an impact on the students' well-being, satisfaction, and academic achievement, but also on their learning satisfaction in online learning environments.

\section{The current study}

Due to the COVID-19 pandemic, almost $90 \%$ of students have been cut off from their classrooms, and the internet has become essential for them to access instructional resources and interact with each other; leading them to become potential excessive and uncontrolled internet users. There are numerous studies that focus on investigating how internet addiction affects students' well-being, satisfaction, and academic achievement (Błachnio, et al., 2019; Cao et al., 2011; Cerniglia et al., 2017; Çikrıkci, 2016; Huang et al., 2009; İskender \& Akin, 2010; Moreno et al., 2013; Sharma \& Sharma, 2018; Stavropoulos et al., 2013; Wang et al., 2013; Yang \& Tung, 2007). Yet the majority of these studies are cross-sectional and the causal relationship is not clear. In addition, these studies in the literature have been conducted to investigate what kind of impact internet addiction had on students' general satisfaction in life. No study in the literature specifically examines the effects of internet addiction on students' learning satisfaction during the COVID-19 pandemic in a longitudinal manner. Therefore, this research study will fill the aforementioned void by examining the associations between internet addiction and online students' learning satisfaction; providing a clearer causal relationship between internet addiction and online students' learning satisfaction in a longitudinal manner, whilst investigating this relationship during the COVID-19 pandemic. 


\section{Methodology}

\section{Sample and procedure}

The dataset was longitudinal, containing two-waves of data with a 3-month lag in between. A total of 301 participants completed the first wave and 265 participants completed the second. The personally identifiable information of the participants was not taken so as to allow anonymous participation, but personal codes were received to enable matching. These codes included: (1) nickname, (2) the first three letters of their mother's first name, (3) the last three letters of their father's first name, and (4) city of inhabitance. Only participants whose data could be matched for both measurements according to their personal codes $(N=249)$ were included in the analysis. The final sample consisted of 158 females $(63.5 \%)$ and 91 males $(36.5 \%)$ from 51 of the 81 cities in Turkey. Participants ranged in age between 18 and $30(\mathrm{M}=19.83, \mathrm{SD}=1.69)$. The majority of participants ( $n=211,84.7 \%$ ) reported that they, or a relative had caught COVID-19. Half of the participants used the internet for 4-5 $\mathrm{h}(n=105,42.2 \%)$, followed by $6 \mathrm{~h}$ and above $(n=92$, $37.0 \%)$, and $3 \mathrm{~h}$ and below $(n=52,20.8 \%)$ per day.

\section{Measures}

\section{Online Learning Satisfaction}

Online learning satisfaction was assessed using the Online Course Satisfaction Scale (OCSS; Bayrak et al., 2020), an 8-item (e.g., "I am satisfied that the online system is easy to use.") self-report scale. Each item in the OCSS is rated on a 5-point scale with a Likert response format (scored 1 -strongly disagree, and 5-strongly agree). The total score ranges between 8 and 40 and a higher score indicates more learning satisfaction. The OCSS has been revealed to have excellent internal consistency reliability $(\alpha>0.93)$ as well as construct validity $\left(\mathrm{CFA}: \chi_{(17)}^{2}=61.27\right.$, GFI $=0.98$; $\mathrm{CFI}=0.99$; NNFI $=0.99$; RMSEA $=0.046$; Bayrak et al., 2020). The OCSS in this study achieved acceptable reliability coefficients (Cronbach's $\alpha$ T1 $=0.928$, Cronbach's $\alpha$ $\mathrm{T} 2=0.949)$.

\section{Internet addiction}

Internet addiction was assessed using Young's Internet Addiction Test-Short Form (YIAT; Pawlikowski et al., 2013; Young, 1998), a 12-item (e.g., "How often do you find that you stay on-line longer than you intended?") self-report scale. Each item in YIAT is rated on a 5-point scale with a Likert response format (scored 1 - never, and
5 - very often). The total score ranges between 12 and 60, and a higher score indicates a higher level of internet addiction. The Turkish version of the scale used in this study was based on the study by Kutlu et al., 2016). The Turkish YIAT has been revealed to have satisfactory internal consistency reliability $(\alpha=0.91)$, as well as construct validity $\left(\mathrm{CFA}: \chi_{(52)}^{2}=144.93\right.$, GFI $=0.93$; $\mathrm{CFI}=0.95$; $\mathrm{IFI}=0.91$; RMSEA $=0.072$; Kutlu et al., 2016). The YIAT in this study achieved acceptable reliability coefficients (Cronbach's $\alpha$ T1 = 0.904, Cronbach's $\alpha$ T2=0.920).

\section{Data Analysis}

First, the descriptive statistics, reliability coefficients (Cronbach's $\alpha$, McDonald's $\omega$, and Guttmann $\lambda 6$ ), and the correlations were calculated using IBM SPSS 22 and JASP 0.11.1. Then, a cross-sectional confirmatory factor analysis at each interval and a longitudinal CFA to examine the entire measurement model was conducted. The longitudinal measurement (configural, metric, and scalar) invariances of the scales were also tested.

To investigate the longitudinal relationships between online learning satisfaction and internet addiction, crosslagged analyses (CLM) in AMOS using the structural equation modeling with a maximum likelihood robust estimator using AMOS Graphics were performed. CLM was chosen because it is one of the techniques that best tests causality (Hamaker et al., 2015). Goodness-of-fit was evaluated using eight indicators: $\chi 2$, Comparative Fit Index (CFI), Goodness of Fit Index (GFI), Normed Fit Index (NFI), Relative Fit Index (RFI), Tucker-Lewis Index (TLI), the Standardized Root Mean Square Residual (SRMR), and Root Mean Square Error of Approximation (RMSEA). On $\mathrm{Hu}$ and Bentler's (1999) recommendation, the CFI, GFI, NFI, RFI, and TLI cut off point was above (0.90), and for the SRMR and the RMSEA it was below (0.80).

\section{Ethics}

In this study, all procedures were taken into account in the context of the Helsinki Declaration. The study was carried out only with volunteers. This research was approved by Artvin Coruh University's Scientific Research and Ethical Review Board (REF =E-18457941-050.99-4971).

\section{Results}

\section{Descriptive Statistics and Correlation Analyses}

The descriptive statistics (mean, SD, etc.), and reliability values for the participants' responses regarding online learning satisfaction and internet addiction are shown in 
Table 1 Descriptive statistics and correlations among the study variables

\begin{tabular}{|c|c|c|c|c|c|c|c|c|c|c|}
\hline \multirow[t]{2}{*}{ Variable } & \multirow[t]{2}{*}{$M$} & \multirow[t]{2}{*}{$S D$} & \multirow[t]{2}{*}{ Skewness } & \multirow[t]{2}{*}{ Kurtosis } & \multirow[t]{2}{*}{$\alpha$} & \multirow[t]{2}{*}{$\omega$} & \multirow[t]{2}{*}{$\lambda 6$} & \multicolumn{3}{|c|}{ Correlations } \\
\hline & & & & & & & & 1 & 2 & 3 \\
\hline 1. Online learning satisfaction $\mathrm{T} 1$ & 32.82 & 9.52 & -.451 & -.333 & .928 & .929 & .940 & _- & & \\
\hline 2. Internet addiction $\mathrm{T} 1$ & 24.98 & 8.83 & .769 & .273 & .904 & .906 & .915 & $-.22^{* *}$ & - & \\
\hline 3. Online learning satisfaction $\mathrm{T} 2$ & 30.53 & 10.17 & -.337 & -.753 & .949 & 949 & .958 & $.15^{*}$ & $-.17^{* *}$ & - \\
\hline 4. Internet addiction $\mathrm{T} 2$ & 24.98 & 8.83 & .769 & .273 & .920 & .921 & .937 & $-.23^{* *}$ & $.99^{* *}$ & $.17^{* *}$ \\
\hline
\end{tabular}

${ }^{*} p<.05 ;{ }^{* *} p<.001$

Table 2 Cross-sectional CFA for Time 1 and Time 2

\begin{tabular}{lccccccccc}
\hline Invariance & $\chi^{2}$ & $d f$ & CFI & GFI & NFI & RFI & TLI & SRMR & RMSEA \\
\hline Model 1 (CFA for Time 1) & .436 & 1 & .999 & .999 & .998 & .996 & .999 & .004 & .001 \\
Model 2 (CFA for Time 2) & 1.32 & 1 & .999 & .997 & .998 & .991 & .998 & & .036 \\
\hline
\end{tabular}

Table 3 Longitudinal measurement invariance of the variables at Time 1 and Time 2

\begin{tabular}{lccccccccccc}
\hline Invariance & $\chi^{2}$ & $d f$ & $\chi^{2} / \mathrm{df}$ & GFI & NFI & RFI & RMSEA & CFI & $\Delta$ CFI & TLI & $\Delta$ TLI \\
\hline Model 3 Configural invariance & 1.76 & 2 & .88 & .998 & .999 & .993 & .001 & .999 & - & .999 & - \\
Model 4 Metric invariance & 6.56 & 4 & 1.64 & .994 & .996 & .987 & .036 & .998 & .001 & .995 & .004 \\
Model 5 Scalar invariance & 20.15 & 11 & 1.83 & .980 & .987 & .986 & .041 & .994 & .004 & .994 & .001 \\
\hline
\end{tabular}

Table 1. Bivariate correlations are also reported in Table 1. Data were distributed normally on all variables. Kurtosis and skewness values ranged respectively from -0.45 to 0.77 , and from -0.89 to 1.81 . The relationship between online learning satisfaction and internet addiction was significant across the surveys.

\section{Longitudinal Measurement Model and Invariance Tests}

Measurement models were tested before evaluating the invariance of constructs over the two surveys. Different CFAs for the measurement models at Times 1 and 2 (see Table 2) were conducted. The measurement model included two latent variables (online learning satisfaction and internet addiction) and four observed variables. The CFA for Time 1 and Time 2 provided an adequate fit to the data. In addition, the results revealed that all factor loadings were significant, $p<0.001$.

Next, a longitudinal CFA was performed. Internet addiction and online learning satisfaction were presented two indicators at each time point (four latent variables and eight observed variables). According to the results, longitudinal CFA fitted the data well: $\chi^{2}=17.51, \mathrm{df}=14$, $\mathrm{CFI}=0.99, \mathrm{GFI}=0.98, \mathrm{NFI}=0.98, \mathrm{RFI}=0.97, \mathrm{TLI}=0.99$, $\mathrm{SRMR}=0.051, \mathrm{RMSEA}=0.032$. Lastly, the longitudinal measurement invariance of the model was investigated. The invariance can be evaluated whereby the value of the $\triangle \mathrm{CFI}$ is equal to or lower than 0.01 , and the value of the $\Delta$ TLI

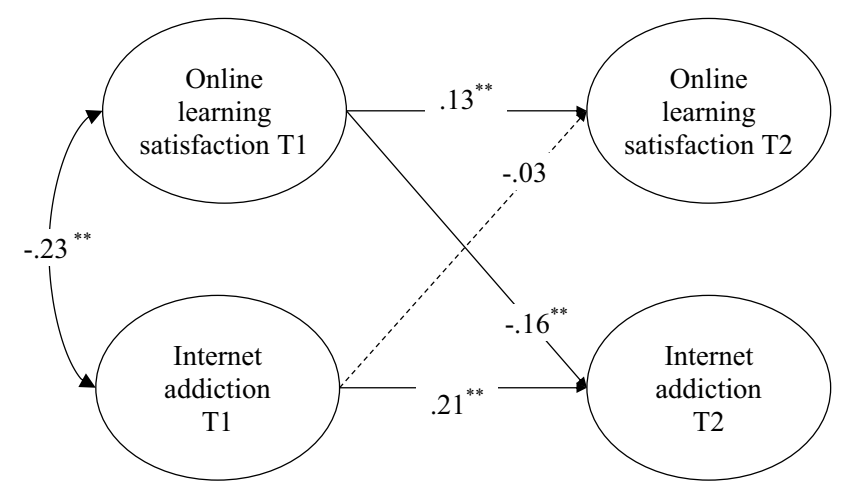

Fig. 1 Cross-lagged panel analysis. Coefficients represent standardized values. T1 Time 1; T2 Time $2 ;{ }^{*} p<.001$; the dashed line is insignificant

is lower than 0.05 (Little, 1997). As shown in Table 3, the $\triangle \mathrm{CFI}$ and $\triangle \mathrm{TLI}$ values were acceptable. Therefore, all of the constructs had similar meanings at the two-time points.

\section{Cross-lagged Path Analytic Model}

To analyze the causal effect of internet addiction on online learning satisfaction, we conducted cross-lagged structural equation modelling as presented in Fig. 1. The findings yielded a good-fitting model: $\chi 2=17.51, \mathrm{df}=14$, $\mathrm{CFI}=0.996$, GFI $=0.979, \mathrm{NFI}=0.987, \mathrm{RFI}=0.976$, $\mathrm{TLI}=0.993, \mathrm{SRMR}=0.023, \mathrm{RMSEA}=0.039$. 
With regards to the cross-lagged relationships, the crosslagged effect of internet addiction at Time 1 on online learning satisfaction at Time 2 was negative and significant ( $\beta=-0.16, p<0.001)$, showing that internet addiction predicts decreases in online learning satisfaction over time. On the other hand, the cross-lagged path from online learning satisfaction at Time 1 to internet addiction at Time 2 was not significant $(\beta=-0.03, p>0.05)$. This suggests that online learning satisfaction does not prospectively predict internet addiction.

\section{Discussion}

Physical distancing interventions social isolation, and quarantines have not only changed traditional face-to-face learning to online learning, but have also led to dramatically increased consumption of the internet during the COVID19 pandemic. Thus, many students who were new to online learning were forced into a new environment and they were required to use the internet more than ever. In this unexpected COVID-19 circumstance, students were more likely to use the internet to attend online classes, to communicate with others, and do activities such as shopping. For these reasons, students had increased use of the internet which caused psychological, social, and school-related problems during the pandemic. The purpose of the present study was to investigate the causal relationship between online learning satisfaction and internet addiction in a longitudinal manner. The results of the two-wave cross-lagged path analysis indicated that there was a negative and strong relationship between online students' learning satisfaction and internet addiction. In effect, internet-addicted students had lower learning satisfaction in online learning environments. In addition to this finding, the results of our study revealed that online students' learning satisfaction did not affect internet addiction.

During the COVID-19 pandemic, students overused the internet because they were required to use it for educational purposes (Dong et al., 2020). Although a reasonable use of the internet is helpful for students, excessive and uncontrolled internet use can lower satisfaction in students' lives (Cerniglia, et al., 2017). Similar to previous research studies (Błachnio, et al., 2019; Bozoglan, et al., 2013; Çikrıkci, 2016; Sharma \& Sharma, 2018; Wang, et al., 2013), the findings of the current study showed that the students' excessive internet use was detrimental to their satisfaction, specifically online learning satisfaction. This study however, also shed light on the direction of the association between internet addiction and learning satisfaction. While internet addiction adversely affected online students' learning satisfaction, the students' learning satisfaction had no impact on internet addiction.
Our results clearly suggest that internet addiction lowered online students' learning satisfaction. This negative relationship could be caused by several reasons. Firstly, the number of hours students spent online dramatically increased because of switching to online learning and the policy of lockdown to control the COVID-19 outbreak. Due to this increase, they became more addicted to the internet. Internet addiction is associated with a wide range of psychological variables such as depression, anxiety, and stress (İskender \& Akin, 2010; Moreno et al., 2013), which may decrease students' learning satisfaction. Secondly, internet addiction has a negative impact on student's motivation to learn and learning strategies, which means students found it harder to organize their learning effectively (Truzoli et al., 2020). It clearly indicates that problematic internet use may lower students' motivation to learn, and hence their learning satisfaction. Last but not least, internet addiction lessens the quality of life (Foerster, \& Röösli, 2017) which causes longterm sleep problems, physical inactiveness, and difficulties in focusing on studying (Casale et al., 2015); factors which may also negatively impact students' learning satisfaction.

\section{Implications}

Our results showed that online learning students experienced excessive internet use due to the closure of schools, which resulted in lower learning satisfaction during the outbreak. Internet addiction causes psychological and social problems such as depression, anxiety, and stress in younger generations' lives; and the mental health of online students was found to be threatened as a direct result of this addiction. Therefore, psychological counseling services need to be provided to students during the COVID-19 pandemic. These counseling services should be organized to assist in preventing problematic internet use among online learning students. Further studies assessing whether psychological consulting prevents the development of internet addiction or not, are recommended particularly during the COVID-19 outbreak.

Since all higher education institutions have switched to online learning, they need to provide appropriate resources and strategies to help reduce students' problematic internet use during the pandemic. Institutions need to offer effective online instruction and psychological coping tools, in addition to social and behavioral support, which may help reduce internet addiction in online learning environments. Furthermore, students need to be conscious of self-monitoring and regulating their internet usage time while going online. It may also be helpful to reduce access to technological devices when engaging in physical or technology-free activities. Plus, maintaining relationships and enjoying social activities are crucial factors to prevent problematic internet use among online learning students. 


\section{Limitations}

This research has also some limitations which should be considered when interpreting the results. Firstly, a convenience sample of undergraduate students was used. Therefore, the findings of this study should be considered in the context of its community and not used to generalise other individuals. Further research could address this limitation by using cross-cultural investigations that examine the relationship between internet addiction and online learning satisfaction. Secondly, it may be necessary to consider increasing the time lag between longitudinal surveys in the future. In the recent study, the interval between the Time 1 and Time 2 surveys was set for three months. Hence, it would be recommendable to conduct follow-up surveys with longer intervals to provide strong evidence of the effects of internet addiction on online students' learning satisfaction. Finally, all the data relied on self-report which are subject to well-known method biases.

\section{Conclusion}

In conclusion, internet-addicted students had lower learning satisfaction in online learning environments. Internet addiction was negatively associated with online learning satisfaction. However, students' learning satisfaction had nothing to do with internet addiction. Therefore, strategies to manage problematic internet use, may have a positive influence on students' learning satisfaction in online learning environments during the COVID-19 pandemic.

Financial Disclosure We did not receive any financial support for the research, authorship, and/or publication of this article. Self-funded.

\section{Declarations}

Ethical Statement All procedures performed in studies involving human participants were in accordance with the ethical standards and with the Helsinki Declaration and its later amendments or comparable ethical standards. Informed consent was obtained from all individual participants included in the study.

Conflict of Interest The authors declare that they have no conflict of interest to disclose.

\section{References}

Bayrak, F., Tibi, M., \& Altun, A. (2020). Development of online course satisfaction scale. Turkish Online Journal of Distance Education, 21(4), 110-123. https://doi.org/10.17718/tojde. 803378
Błachnio, A., Przepiorka, A., Benvenuti, M., Mazzoni, E., \& Seidman, G. (2019). Relations between Facebook intrusion, Internet addiction, life satisfaction, and self-esteem: A study in Italy and the USA. International Journal of Mental Health and Addiction, 17(4), 793-805. https://doi.org/10.1007/ s11469-018-0038-y

Bolliger, D.U. (2004). Key Factors for Determining Student Satisfaction in Online Courses. International Journal on E-Learning, 3(1), 61-67. Norfolk, VA: Association for the Advancement of Computing in Education (AACE). Retrieved January 1, 2021 from https://www.learntechlib.org/primary/p/2226/

Bozoglan, B., Demirer, V., \& Sahin, I. (2013). Loneliness, selfesteem, and life satisfaction as predictors of Internet addiction: A cross-sectional study among Turkish university students. Scandinavian Journal of Psychology, 54(4), 313-319. https:// doi.org/10.1111/sjop.12049

Cao, H., Sun, Y., Wan, Y., Hao, J., \& Tao, F. (2011). Problematic Internet use in Chinese adolescents and its relation to psychosomatic symptoms and life satisfaction. BMC Public Health, 11(1), 1-8. https://doi.org/10.1186/1471-2458-11-802

Casale, S., Lecchi, S., \& Fioravanti, G. (2015). The association between psychological well-being and problematic use of Internet communicative services among young people. The Journal of Psychology, 149(5), 480-497. https://doi.org/10.1080/00223 980.2014 .905432

Cerniglia, L., Zoratto, F., Cimino, S., Laviola, G., Ammaniti, M., \& Adriani, W. (2017). Internet Addiction in adolescence: Neurobiological, psychosocial and clinical issues. Neuroscience \& Biobehavioral Reviews, 76, 174-184. https://doi.org/10.1016/j. neubiorev.2016.12.024

Çikrıkci, Ö. (2016). The effect of internet use on well-being: Metaanalysis. Computers in Human Behavior, 65, 560-566. https:// doi.org/10.1016/j.chb.2016.09.021

Dong, H., Yang, F., Lu, X., \& Hao, W. (2020). Internet addiction and related psychological factors among children and adolescents in China during the coronavirus disease 2019 (COVID-19) epidemic. Frontiers in Psychiatry, 11, 751. https://doi.org/10.3389/ fpsyt.2020.00751

Duan, L., Shao, X., Wang, Y., Huang, Y., Miao, J., Yang, X., \& Zhu, G. (2020). An investigation of mental health status of children and adolescents in china during the outbreak of COVID-19. Journal of Affective Disorders, 275, 112-118. https://doi.org/ 10.1016/j.jad.2020.06.029

Franchi T. (2020). The impact of the covid-19 pandemic on current anatomy education and future careers: A student's perspective. Anatomical Sciences Education, 13(3), 312-315. https://doi.org/ 10.1002/ase. 1966

Foerster, M., \& Röösli, M. (2017). A latent class analysis on adolescents media use and associations with health related quality of life. Computers in Human Behavior, 71, 266-274. https://doi. org/10.1016/j.chb.2017.02.015

Gómez-Galán, J., Martínez-López, J. Á., Lázaro-Pérez, C., \& Sarasola Sánchez-Serrano, J. L. (2020). Social networks consumption and addiction in college students during the COVID-19 pandemic: Educational approach to responsible use. Sustainability, 12(18), 7737. https://doi.org/10.3390/su12187737

Green, K. C. (2010). The Campus Computing Survey. Encino, CA: The Campus Computing Project. Retrieved from https://www. campuscomputing.net/2010-campus-computing-survey

Griffiths, M. (2000). Does Internet and computer" addiction" exist? Some case study evidence. CyberPsychology and Behavior, 3(2), 211-218. https://doi.org/10.1089/109493100316067

Hamaker, E. L., Kuiper, R. M., \& Grasman, R. P. P. P. (2015). A critique of the cross-lagged panel model. Psychological Methods, 20(1), 102-116. https://doi.org/10.1037/a0038889 
Hu, L. T., \& Bentler, P. M. (1999). Cutoff criteria for fit indexes in covariance structure analysis: Conventional criteria versus new alternatives. Structural equation modeling: a multidisciplinary journal, 6(1), 1-55.https://doi.org/10.1080/10705519909540118

Huang, R. L., Lu, Z., Liu, J. J., You, Y. M., Pan, Z. Q., Wei, Z., He, Q., \& Wang, Z. Z. (2009). Features and predictors of problematic internet use in Chinese college students. Behaviour \& Information Technology, 28(5), 485-490. https://doi.org/10.1080/01449 290701485801

Ilgaz, H., \& Gülbahar, Y. (2015). A snapshot of online learners: e-Readiness, e-Satisfaction and expectations. International Review of Research in Open and Distributed Learning, 16(2), 171-187.https://doi.org/10.19173/irrodl.v16i2.2117

Iskender, M., \& Akin, A. (2010). Social self-efficacy, academic locus of control, and internet addiction. Computers \& Education, 54(4), 1101-1106. https://doi.org/10.1016/j.compedu.2009.10.014

Kaur, G. (2020). Digital Life: Boon or bane in teaching sector on COVID-19. CLIO an Annual Interdisciplinary Journal of History, 6(6), 416-427.

Korkmaz, G., \& Toraman, Ç. (2020). Are we ready for the postCOVID-19 educational practice? An investigation into what educators think as to online learning. International Journal of Technology in Education and Science (IJTES), 4(4), 293-309. https://doi.org/10.46328/ijtes.v4i4.110

Kutlu, M., Savci, M., Demir, Y., \& Aysan, F. (2016). Turkish adaptation of Young's Internet Addiction Test-Short Form: a reliability and validity study on university students and adolescents. Anadolu Psikiyatri Dergisi, 17(S1), 69-76. https://doi.org/10.5455/apd. 190501

Liaw, S. S. (2008). Investigating students' perceived satisfaction, behavioral intention, and effectiveness of e-learning: A case study of the Blackboard system. Computers \& Education, 51(2), 864-873. https://doi.org/10.1016/j.compedu.2007.09.005

Little, T. D. (1997). Mean and covariance structures (MACS) analyses of cross-cultural data: Practical and theoretical issues. Multivariate Behavioral Research, 32(1), 53-76. https://doi.org/10.1207/ s15327906mbr3201_3

Mehrotra, C. M., Hollister, C. D., \& McGahey, L. (2001). Distance learning: Principles for effective design, delivery, and evaluation. Sage Publications Inc.

Moore, J. (2014). Effects of online interaction and instructor presence on students' satisfaction and success with online undergraduate public relations courses. Journalism \& Mass Communication Educator, 69(3), 271-288. https://doi.org/10.1177/1077695814 536398

Moreno, M. A., Jelenchick, L. A., \& Christakis, D. A. (2013). Problematic internet use among older adolescents: A conceptual framework. Computers in Human Behavior, 29(4), 1879-1887. https:// doi.org/10.1016/j.chb.2013.01.053

Naveh, G., Tubin, D., \& Pliskin, N. (2010). Student LMS use and satisfaction in academic institutions: The organizational perspective. The Internet and Higher Education, 13(3), 127-133. https://doi. org/10.1016/j.iheduc.2010.02.004

Nielsen Global Media. (2020). The impact of COVID-19 on media consumption across North Asia. Retrieved from https://www.nielsen. com/wp-content/uploads/sites/3/2020/03/The-Impact-of-COVID19-on-Media-Consumption-Across-North-Asia.pdf
Nortvig, A. M., Petersen, A. K., \& Balle, S. H. (2018). A Literature Review of the Factors Influencing E-Learning and Blended Learning in Relation to Learning Outcome, Student Satisfaction and Engagement. Electronic Journal of E-Learning, 16(1), 46-55.

Pawlikowski, M., Altstötter-Gleich, C., \& Brand, M. (2013). Validation and psychometric properties of a short version of young's internet addiction test. Computers in Human Behavior, 29(3), 1212-1223.https://doi.org/10.1016/j.chb.2012.10.014

Republic of Turkey Ministry of Health. (2021). Retrieved from https:// covid19.saglik.gov.tr/

Roe, D., Carley, S., \& Sherratt, C. (2010). Potential and limitations of e-learning in emergency medicine. Emergency Medicine Journal, 27(2), 100-104. https://doi.org/10.1136/emj.2008.064915

Sharma, A., \& Sharma, R. (2018). Internet addiction and psychological well-being among college students: A cross-sectional study from Central India. Journal of Family Medicine and Primary Care, 7(1), 147-151. https://doi.org/10.4103/2Fjfmpc.jfmpc_189_17

Stavropoulos, V., Alexandraki, K., \& Motti-Stefanidi, F. (2013). Recognizing internet addiction: Prevalence and relationship to academic achievement in adolescents enrolled in urban and rural Greek high schools. Journal of Adolescence, 36(3), 565-576. https://doi.org/ 10.1016/j.adolescence.2013.03.008

Sun, P. C., Tsai, R. J., Finger, G., Chen, Y. Y., \& Yeh, D. (2008). What drives a successful e-Learning? An empirical investigation of the critical factors influencing learner satisfaction. Computers \& Education, 50(4), 1183-1202. https://doi.org/10.1016/j.compe du.2006.11.007

UNESCO. (2020). COVID-19 educational disruption and response. https://en.unesco.org/covid19/educationresponse

Truzoli, R., Viganò, C., Galmozzi, P. G., \& Reed, P. (2020). Problematic internet use and study motivation in higher education. Journal of Computer Assisted Learning, 36(4), 480-486. https://doi.org/ $10.1111 /$ jcal.12414

Wang, L., Luo, J., Bai, Y., Kong, J., Luo, J., Gao, W., \& Sun, X. (2013). Internet addiction of adolescents in China: Prevalence, predictors, and association with well-being. Addiction Research \& Theory, 21(1), 62-69. https://doi.org/10.3109/16066359.2012.690053

World Health Organization. Naming the coronavirus disease (COVID19) and the virus that causes it. Published online 2020, April 20. Available at: https://www.who.int/emergencies/diseases/novelcoronavirus-2019/technical-guidance/naming-the-coronavirusdisease-(covid-2019)-and-the-virus-that-causes-it

Yang, S. C., \& Tung, C. J. (2007). Comparison of Internet addicts and non-addicts in Taiwanese high school. Computers in Human Behavior, 23(1), 79-96. https://doi.org/10.1016/j.chb.2004.03.037

Young, K. S. (1998). Caught in the net: How to recognize the signs of internet addiction--and a winning strategy forrecovery. John Wiley \& Sons.

Yukselturk, E., \& Yildirim, Z. (2008). Investigation of interaction, online support, course structure and flexibility as the contributing factors to students' satisfaction in an online certificate program. Journal of Educational Technology \& Society, 11(4), 51-65.

Publisher's Note Springer Nature remains neutral with regard to jurisdictional claims in published maps and institutional affiliations. 